\title{
G sonstem \\ Ipsilateral Vs Controlateral Approach in Tuberculum Sellae Meningiomas Surgery. A Retrospective Comparative Study
}

\section{Lucas Troude ( $\square$ lucas.troude@ap-hm.fr)}

Aix-Marseille Universite https://orcid.org/0000-0003-2995-4820

\section{Mohamed Boucekine}

Department of statistical analysis, Faculté des Sciences médicales et Paramédicales, Aix-Marseille Université (AMU) - 27 bd Jean Moulin 13385 Marseille, FRANCE

\section{Guillaume Baucher}

Department of Neurosurgery, North University Hospital, APHM-AMU - Chemin des Bourrely, Marseille 13015, FRANCE

\section{Kaissar Farah}

Department of Neurosurgery, Timone University Hospital, APHM-AMU - 264 Rue Saint-Pierre, 13385 Marseille, FRANCE

\section{Sébastien Boissonneau}

Department of Neurosurgery, Timone University Hospital, APHM-AMU - 264 Rue Saint-Pierre, 13385 Marseille, FRANCE

\section{Stéphane Fuentes}

Department of Neurosurgery, Timone University Hospital, APHM-AMU - 264 Rue Saint-Pierre, 13385 Marseille, FRANCE

\section{Thomas Graillon}

Department of Neurosurgery, Timone University Hospital, APHM-AMU - 264 Rue Saint-Pierre, 13385 Marseille, FRANCE

\section{Henry Dufour}

Department of Neurosurgery, Timone University Hospital, APHM-AMU - 264 Rue Saint-Pierre, 13385 Marseille, FRANCE

\section{Research Article}

Keywords: Anosmia, Tuberculum sellae meningioma, Tumor control, Visual acuity, Visual field defect Posted Date: March 19th, 2021

DOl: https://doi.org/10.21203/rs.3.rs-325053/v1 
License: (c) (i) This work is licensed under a Creative Commons Attribution 4.0 International License. Read Full License

Version of Record: A version of this preprint was published at Neurosurgical Review on April 22nd, 2021. See the published version at https://doi.org/10.1007/s10143-021-01536-y. 


\section{Abstract}

Background: Most of tuberculum sellae meningiomas (TSM) show asymmetric growth. They are usually resected through ipsilateral approaches. The access of the inferior-medial side of the ipsilateral optic nerve might be challenging, which result in increased manipulation of the compromised optic nerve. The contralateral approach has been described to avoid these technical difficulties.

Objective: Assessing the long term visual and olfactory outcome, as well as recurrence rate in patients operated for TSM through ipsi- or contralateral approaches.

Methods: Single center retrospective cohort study about 94 patients operated on between March 2000 and April 2018.

Results: $70 \%$ of the preoperative visual acuity loss totally resolved (44\%) or showed varying degrees of improvement (26\%) after surgery. Seventy-two percent of the preoperative visual field defects evolved favorably (44\% recovery, $28 \%$ improvement). Eight patients showed aggravated visual disturbances ( $9 \%$ ). A contralateral approach seemed to be predictive of visual field defects improvement after surgery $(\mathrm{OR}=0.4)$, with borderline significant results $(\mathrm{p}=.08)$. There was a higher rate of postoperative olfactory nerve impairment after a contralateral approach $(37 \% \mathrm{vs} 17 \%, p=.03)$. Total removal of the tumor fragment entering the optic canal was accomplished in $96 \%$ in the contralateral vs $75 \%$ in the ipsilateral group $(p=.04)$. The 2-, 5- \& 7-year tumor progression free survival were 100\% in the Simpson Grade 2 group, and $85 \%(n=17), 74 \%(n=11) \& 67 \%(n=5)$ in the Simpson Grade 4 group, respectively $(p=.00)$.

Conclusion: Resection of tuberculum sellae meningiomas through a contralateral approach seems to provide better visual outcome and tumor control at the cost of increased olfactory nerve disorders.

\section{Introduction}

Tuberculum sellae meningiomas (TSMs) represent approximately $5-10 \%$ of intracranial meningiomas [1]. TSMs usually extend to one or both inferomedial part of the optic canal (OC) $[8,13,17,23]$, which leads to compression of the optic nerve (ON) superiorly against the falciform ligament $[17,23,29]$, or adjacent OC invasion by the tumor (from 20 to $75 \%$ of cases) (Figure 1) [11,13,17,23]. Visual disturbances are therefore the foremost symptoms (77-87.5\%) [1,11,23,24,28,32].

The ultimate goal in TSM surgery is gross total resection (GTR), aiming at visual stabilization or recovery. Most of TSMs show asymmetric growth, originating laterally on the tuberculum sellae or optic sulcus [23]. These tumors are usually resected through ipsilateral approaches either to preserve the noncompromised $\mathrm{ON}$ function or because this is the shorter access to reach the lateral border of the tumor [15]. However, the access of the inferior-medial side of the ipsilateral ON might be challenging in this configuration, which result in increased manipulation of the compromised ON (Figure 2) $[4,12,24,28,32]$. Bony unroofing of the ipsilateral OC or extradural resection of the anterior clinoid process (ACP) might be necessary in order to expose its distal part, with additional risk to damage the 
compressed ON $[27,31,32,35,36]$. Some surgeons are used to operate by one side regardless the predominant side of the TSM [12]. To avoid manipulation of the ON, transtubercular approach can be an option, but a high rate of sino-nasal dysfunction and $12-25 \%$ postoperative CSF leaks resulting in $4-5 \%$ meningitis have been reported after endoscopic transsphenoidal approaches $[3,9,10,20,22,25]$.

The contralateral approach provides a direct view of the inferomedial aspect of the compromised OC and $\mathrm{ON}$. The tumor can be therefore removed with minimal manipulation of the $\mathrm{ON}[11,18]$. However, the route to reach the contralateral $\mathrm{OC}$ is longer in this configuration, resulting in additional frontal lobe retraction that can impact the integrity of the olfactory tracts.

We retrospectively analyzed our series of 94 consecutive patients operated over 18 years through ipsi- or contralateral approaches, assessing long term results with particular interest to visual and olfactory outcomes, and recurrence rate.

\section{Methods}

All consecutive patients who underwent surgical treatment for tuberculum sellae meningioma between March 2000 and April 2018 were included in this retrospective cohort study. Informed consent was obtained from all patients, and the French Neurosurgical College Institutional Review Board approved this study (reference: IRB00011687 - College de neurochirurgie IRB \#1: 2020/33).

\section{Patient characteristics:}

Patients underwent preoperative ophthalmologic examinations including visual acuity (LogMar) and visual field test (Goldmann perimetric examination). Olfaction was subjectively assessed by the ability to smell common odors. Olfactory status was then classified as anosmia, hyposmia or normal. Preoperative 3-Tesla brain magnetic resonance imaging (MRI) was performed in all patients to evaluate the location, tumor characteristics (including volumetric measurements performed on axial Gadolinium-enhanced T1 weighted MR images - iPlan 3.0 Cranial Brainlab, Munich, Germany). Surgical findings such as extent of resection, olfactory nerve avulsion were recorded.

\section{Surgical protocol}

At the beginning of our experience, we used to operate TSMs throught a right side approach. During this period of time, we noticed that it was easier to resect tumor entering into the contralateral than the ipsilateral OC, without manipulation of the corresponding $\mathrm{ON}$. Thereby, our attitude progressively turned out to operate TSMs through a contralateral approach in case of OC unilateral involvement. Two groups have therefore been constituted retrospectively depending on the dominant compression side of the TSM.

A fronto-temporal curvilinear skin incision was carried-out. A frontolateral craniotomy was then shaped with no need for an orbital rim removal. The first intra-dural step intended to obtain CSF depletion by opening the sylvian and ipsilateral carotid cisterns, in order to minimize brain retraction. The use of a selfretaining retractor was unnecessary. 
Tumor resection started by coagulation of its insertion in order to devascularize and mobilize the meningioma, followed by central debulking. The tumor volume reduction facilitated the identification of the natural capsuloarachnoid dissection plan between the tumor and suprasellar arachnoid elements, within which run the feeding arteries of the optic apparatus (Figure 3) [5,33,39]. A sharp dissection was performed along that plane and the optic sulcus to expose the inferomedial aspect of the compromised ON. At this step, the intracanalar part of the tumor could be removed by gentle traction, or with the use of an arachnoid hook. Finally, the posterior part of the tumor was resected. The entire procedure could be achieved without any manipulation of the compromised nor non-compromised ON (Figure 4).

\section{Postoperative Outcome:}

The clinical examination included ophthalmologist investigations 3 months after surgery and thereafter yearly to evaluate the postoperative visual acuity and visual field, and evaluation of the olfactory status. The postoperative tumor residue was assessed using a Gadolinium-enhanced MRI 3 to 6 months after surgery. Extent of resection was assessed by the Simpson grading system [5,37]. Gross total resection was defined as $100 \%$ tumor clearance on the surgeon assessment, and confirmed by the first postoperative MRI. The patient was then allocated into a Wait-\&-re-Scan policy.

\section{Statistical Analysis}

All statistical analyses were performed using IBM Corp. Released 2012. IBM SPSS Statistics for Windows, Version 21.0. Armonk, NY: IBM Corp. The significance of baseline differences was determined by the chisquare test or Fisher's exact test, and by the unpaired t-test or Mann-Whitney test, as appropriate. Univariate and multivariate logistic regression models were used to determine the contribution of these variables on postoperative visual outcome. Odds ratios (OR) and $95 \%$ confidence intervals $(95 \% \mathrm{Cl})$ are reported. Variables showing $\mathrm{p}<0.2$ in the univariate analysis were included in multivariate analysis. A twosided $p$-value of less than .05 was considered to indicate statistical significance.

\section{Results}

\section{Population Study: (Table1)}

Ninety-four consecutive patients operated on for a tuberculum sellae meningioma were enrolled in this study, including 83 females (88\%) and 11 males (12\%), with a mean age of 55 years (range 21-86).

\section{Clinical Features: (Table1)}

The foremost symptoms were the visual disturbances (91\%). Eighty patients (85\%) reported decrease of vision. Sixty-one percent of patients presented unilateral visual acuity loss, and $24 \%$ manifested bilateral impairments. The visual acuity ranged widely from normal vision (19 patients - $20 \%$ ) to blindness (2 patients - 2\%). Ninety-four percent of the patients showed VFD on Goldmann perimetric examination. The mean duration of visual symptoms was 8 months (range 0.5-48 / median 6 months). 
Fourteen patients (15\%) suffered from nonspecific headaches, anosmia (3\%), seizure (1\%). One patient (1\%) presented with symptoms related to hypopituitarism.

Radiological Features: (Table1)

The mean tumor volume was $5.6 \mathrm{cc}$ (range 0.7-14.5 / median $4.1 \mathrm{cc}$ ); the mean maximal diameter was 25 $\mathrm{mm}$ (range 10-78 / median $24 \mathrm{~mm}$ ). The meningioma showed asymmetric growth with paramedian insertion in $84 \%$ of cases, while a median insertion was found in 15 patients (16). A median insertion was statically more frequently found in the male than female population ( $45 \% \mathrm{vs} 12 \%$, respectively $-p=0.04$ ). The dominant extension side was correlated to the clinical visual impairments in all cases, which was determinant to define the side of the approach.

\section{Surgical Features: (Table1)}

According to the main $\mathrm{ON}$ anatomical compression, $38 \%$ of the tumors (36 patients) were operated on through a contralateral craniotomy, whereas 43 patients (46\%) underwent an ipsilateral approach, regardless the side of poorer vision. Patients whom presented midline lesions ( 15 patients $-16 \%)$ compromising bilateral vision underwent a right-sided craniotomy. Those patients have been excluded from the logistic regression analysis. Tumors originated from optic sulcus in $32 \%$ of cases, from TS in $19 \%$ and both optic sulcus and TS in 17\%; from OC in 15\%, both optic sulcus and OC in $7 \%$, and both tuberculum sellae and OC in $9 \%$ of cases.

Tumor entering into the $\mathrm{OC}$ was found in 59 patients (63\%). Only 3 patients had both canals involved (3\%). Fifty-seven percent (57\%) of the patients presenting with an OC involvement were operated through a contralateral approach, whereas $43 \%$ underwent an ipsilateral approach.

The tumor was invading the pia-mater of the frontal lobe in 5 cases (5\%). The ON and pituitary stalk were anatomically preserved in all patients. The ipsilateral olfactory nerve was damaged or avulsed due to the spontaneous collapse of the frontal lobe during surgery in 34 cases (36\%) (Figure 5). There was a higher rate of olfactory nerve avulsion in patients operated through a contralateral than an ipsilateral approach ( $46 \%$ vs $26 \%$ respectively, $p=.04$ ).

Seventy patients underwent a Simpson Grade 2 resection (74\%). In 24 patients (26\%), the tumor was resected subtotally because of severe adhesion to the ON (16 patients) or ICA ( 2 patients), or extension to the cavernous sinus ( 6 patients). A tumor residue was left near the $\mathrm{ON}$ in $33 \%$ of cases when tumor resection was performed through an ipsilateral approach, while only $17 \%$ when a contralateral approach was preferred $(p=.11)$. In case of OC invasion, the tumor fragment could be successfully resected in $94 \%$ of cases through a contralateral whereas $75 \%$ through an ipsilateral approach $(p=0.04)$.

Eight meningiomas (9\%) were classified as WHO grade II tumors. The mean duration of surgery was 140 min (range 60-350 / median $138 \mathrm{~min}$ ). The mean hospital stay was 10 days (range 4-41 / median 8 days). 


\section{Visual outcome:}

Forty-four percent of the preoperative visual acuity loss totally resolved after surgery. Twenty six had varying degrees of improvement (total of $70 \%$ favorable outcome), while $24 \%$ were stationary. In the same way, $72 \%$ of the VFD evolved favorably (44\% recovery, $28 \%$ improvement), while $19 \%$ remained unchanged. Eight patients showed long-term postoperative aggravated visual disturbances (9\%). A contralateral approach seemed to be predictive of VFD improvement after surgery $(O R=0.4)$, with borderline significant results $(p=.08)$.

\section{Predictive factors of unfavorable postoperative visual acuity outcome (Table 2)}

Epidemiological factors:

Age and duration of symptoms were associated with non-recuperation of preoperative visual acuity loss as continuous variables ( $p=.03 \& p=.00$, respectively). Patients who presented with a preoperative visual acuity $>$ to LogMar 1.3 experienced poorer recovery after surgery than those with visual acuity $\leq$ to LogMar 1.3 (41\% favourable outcome vs $79 \%$, respectively - OR=27.7, $p=.00$ ). The tumor volume appeared to be related to the visual outcome as a continuous variable: the larger the meningioma, the more likely was the patient to recover after surgery $(p=.00-0 R=.73)$.

Intraoperative factors:

Seventy-four percent of the patients who presented with an optic canal involvement showed favorable visual outcome, versus $62 \%$ when the $\mathrm{OC}$ was freed from tumor $(\mathrm{p}=.09)$. The extent of resection was associated with better visual outcomes: the visual acuity loss improved in $77 \%$ of the patients who underwent Simpson Grade 2 resection, whereas $45 \%$ after subtotal Simpson Grade 4 resection (OR=18.9; $\mathrm{p}=.01)$.

\section{Predictive factors of unfavorable postoperative visual field outcome (Table 3)}

A young age appeared to be related to improvement of the VFD after surgery $(p=.00)$. The preoperative status of the visual field was statistically associated with its postoperative evolution. Patients harboring preoperative complete hemianopia experienced poorer recovery than those who presented with incomplete preoperative VFD ( $51 \%$ vs $89 \%$ of recuperation, respectively - OR=8, $p=.00$ ).

\section{Olfactory status:}

Two patients who presented with preoperative anosmia remained unchanged over time. Postoperative olfactory nerve disorders were transient in two cases only. Postoperative olfactory impairment were observed in 24 patients (26\%). Fourteen patients (15\%) retained long-term postoperative hyposmia, whereas $10(11 \%)$ reported complete anosmia. There was significantly a higher rate of new permanent postoperative olfactory nerve impairment in patients operated through a contralateral than an ipsilateral approach ( $37 \%$ vs $17 \%$ respectively, $p=.03)$. 


\section{Other complications:}

The other immediate postoperative complications were seizure (4 patients - 4\%), operative site hematoma (5 patients $-5 \%$ ) and prolonged hospital stay in the ICU (3 patients $-3 \%$ ), transient diabetes insipidus (4 patient $-4 \%$ ), meningitis ( 1 patient $-1 \%$ ), chronic subdural hematomas ( 2 patients $-2 \%$ ) and one pseudo-meningocele requiring ventriculo-peritoneal shunting (1\%). Intraoperative ICA injury occurred in 1 patient $(1 \%)$, managed by clipping and exclusion of the $\mathrm{CA}$, who experienced postoperative transient hemiparesis with further complete recovery. Two patients $(2 \%)$ required cosmetic revision surgery, including late wound erosion on a titanium plate. None of the patients reported CSF leak, while 12 (13\%) had frontal sinus opening during surgery (managed using TachoSil ${ }^{\circledR}$ Fibrin Sealant Patch - Baxter International Inc. Deerfield, Illinois).

Tumor Control: (Figure 6)

The overall mean radiological follow-up was 63 months (2-210 / median 50 months). Ten (11\%) cases of regrowth were diagnosed during the FU period, with a mean delay from surgery to regrowth of 73 months (range 13-190 / median 56). Two of them had received Simpson Grade 2 resection, while 8 harbored a postoperative residue ( $97 \%$ vs $64 \%$ tumor control in these selected groups, respectively $-p=.00$ ). Half of the tumor regrowth were detected during radiological follow-up examination, whereas the other half presented with a worsening of vision. The 2-, 5- \& 7-year tumor progression free survival (PFS) were 100\% $(n=41), 100 \%(n=22) \& 100 \%(n=11)$ in the Simpson Grade 2 group, and 85\% $(n=17), 74 \%(n=11) \& 67 \%$ $(n=5)$ in the Simpson Grade 4 group, respectively $(p=.00)$.

Two of those growing residues were treated with complementary GKS, 4 received postoperative radiotherapy. Four underwent salvage surgery (5\%). One of these patient presented continuous growth of the residue after the second stage surgery (WHO grade II meningioma). He received adjuvant postoperative radiotherapy, then chemotherapy $\left(\right.$ Avastin $\left.^{\circledR}\right)$. This 79 years old patient died 38 months after surgery.

\section{Discussion}

Optic nerve function recovery is the most essential issue in TSM surgery. We reported in our series 70\% favorable postoperative visual outcome (for both visual acuity loss and VFD), while $21 \%$ remained unchanged despite decompression and $9 \%$ of the patients showed long-term postoperative aggravated visual disturbances. Not surprisingly, an increasing age and visual symptoms duration were associated with non-recuperation of preoperative visual acuity loss ( $p=.03 \& p=.00$, respectively) [23]. In the same way, it appears that the depth of preoperative visual impairment, both visual acuity $(p=.00-0 R=27.6)$ and visual field deficiency $(\mathrm{p}=.00-\mathrm{OR}=7.9)$ were strongly correlated with unfavourable postoperative outcome. However, we did not expect that the preoperative tumor volume and optic canal involvement would be identified as predictive factors of postoperative visual loss recovery $(p=.00 \& p=.09$, respectively). If we think this through, and considering the high rate of GTR in our study, the greater ON 
decompression obtained in both cases may explain why these patients are likely to have better postoperative visual outcome.

The recurrence rate is the second major concern in the management of TSMs. We related $11 \%$ rate of regrowth in the present study, which is similar to those reported in the recent literature

$[11,13,17,20,23,25,34]$. However, the median follow-up time (50 months) was shorter than the mean delay between surgery and regrowth reported in our study (73 months); new cases are likely to be diagnosed in the next few years. The tumor control rate was $97 \%$ in the GTR group, versus $64 \%$ in patients who underwent subtotal resection ( $p=.00)$. It is well established that Simpson Grade 4 is more at risk for recurrence than Simpson Grade 2 resection [26]. Half of the tumor regrowth were detected during radiological follow-up examination, whereas the other half presented with a worsening of vision. Those patients required a salvage surgery. The other half was proposed for GKS or radiotherapy.

When the side of the approach was not taken into account, the global outcome is concordant with the recent literature $[11,13,17,20,23,25,34]$. The aim of the present study was to demonstrate whether or not the contralateral was associated to better visual outcome than the ipsilateral approach, in TSM surgery.

TSMs arose from the lateral end portion of the tuberculum sellae in $85 \%$ of cases, whereas $15 \%$ expanded from the midline area [23]. As the tumor grows, the ipsilateral ON is displaced superiorly or superolaterally against the sharp edge of the falciform ligament, resulting in indentation and angulation of ON in early stage (Figure 1) $[8,13,15,23]$. Thereby, the inferomedial aspect of the ON is in a blind area, resulting in more manipulation of the compromised $\mathrm{ON}$ if operated via the ipsilateral route. Additionally, the tumor extending into the $\mathrm{OC}(63 \%)$ is responsible of a severe compression of the $\mathrm{ON}$, even if the extracanalicular part of the meningioma is small.

Unroofing the ipsilateral $\mathrm{OC}$ can be advocated to liberate the $\mathrm{ON}$ [30], although this technique is not freed from damages to the compromised $\mathrm{ON}$ and do not avoid its manipulation [30,36]. In case of true invasion of the $\mathrm{OC}$ by the tumor, which means extension of the tumor insertion base inside the $\mathrm{OC}$, its bony unroofing is legitimate to complete the tumor resection and control its insertion. In our series, we never had to perform such a technique. TSMs originated from the optic foramen in $31 \%$ of cases, but no case of tumor insertion base inside the OC was recorded.

Some authors have recommended carrying out an extradural resection of the ACP $[5,31,35]$. We consider this time-consuming procedure as an amazing progress in the management of ACP meningiomas to obtain early proximal control of the $\mathrm{ON}$ and ICA. Nevertheless, the $\mathrm{ON}$ is displaced medially by the tumor in that configuration. On the opposite, as the $\mathrm{ON}$ is dislocated laterally in case of TSM meningioma, we consider the drilling unsafe due to the risk of direct or thermal damages [21]. As our proposal, the contralateral approach has been described to surmount those limitations of the ipsilateral approaches $[11,18]$.

On the one hand, approaching TSMs through the contralateral side provide direct visualization of the medial OC without $\mathrm{ON}$ mobilization. In our experience, tumor entering into the $\mathrm{OC}$ is easily resected 
through a contralateral approach with no need for adjunctive bony unroofing. In most of the cases, this tumor extension is solidary to the meningioma during the manipulation of its interoptic portion, and resected altogether. In cases of tumor fragmentation, the intracanalar part of the tumor could be removed with the use of an arachnoid hook. Eighty-free percent of the patients operated on through a contralateral approach had received Simpson Grade 2 resection (vs 67\% when an ipsilateral approach was performed $p=0.11)$. The extent of resection was correlated to better visual outcome in our study $(p=.01)$. Moreover, the preoperative tumor volume and $\mathrm{OC}$ involvement have been identified as predictive factors of postoperative visual loss recovery ( $p=.00 \& p=.09$, respectively). Tumor entering into the $O C$ was easily resected through a contralateral approach, which eliminated a critical compression point of the $\mathrm{ON}$, as compared to the ipsilateral approach (respectively $96 \%$ vs $75 \%$ complete $O C$ released, $p=0.04$ ). Thereby, it seems that the contralateral approach led to a better VFD improvement rate than the ipsilateral approach $(\mathrm{OR}=0.4-\mathrm{p}=.08)$. Furthermore, as Simpson Grade 4 resection has been identified as a predictive factor of tumor recurrence, a contralateral approach seems to be more appropriate in case of optic canal involvement to avoid long-term tumor regrowth.

On the other hand, we have observed a higher rate of new permanent postoperative olfactory nerve impairment in patients operated through a contralateral than an ipsilateral approach (37\% vs $17 \%$ respectively, $\mathrm{p}=.03$ ). Unfortunately, intraoperative olfactory tract avulsion and postoperative olfactory disorders in TSM surgery have not been systematically evaluated in the literature. A few series have reported $6-15 \%$ olfactory nerve deterioration during surgery through ipsilateral pterional or frontolateral approaches $[12,17,19,27,28,36]$, but have not evaluated its postoperative subjective or objective disorders. Two series had yielded similar rates of olfactory disturbances after a contralateral than those reported after an ipsilateral approach $(<10 \%)[9,11]$. These authors performed a first-step dissection of the olfactory tract from the frontal lobe to avoid any tearing or avulsion during surgery. This may contribute to reduce the incidence of postoperative olfactory disturbances [6,7]. Anyway, the postoperative olfactory function outcome seem to be better after pterional and frontolateral than anterior interhemispheric approaches. Indeed, due to the permanent exposition of the olfactory tracts during tumor resection in this configuration, a high rate of olfactory nerve avulsion (from 11 to $40 \%$ ) despite careful early dissection have been reported $[2,14,16,28,36,38]$.

Last but not least, the contralateral approach involves the risk of damaging the noncompromised ON (5$12,5 \%)[11,17]$. The rate of aggravated visual disturbances was similar between both groups ( $9 \%$ vs $10 \%$ in the ipsi- and contralateral groups, respectively - p>0.05). In our series, one patient who underwent a contralateral approach experienced long term postoperative worsening of the non-compromised ON visual function (2\%). In our mind, the use of a frontolateral approach provides an oblique surgical window of the interoptic area, while a pterional approach along the sphenoidal crest results in manipulations of the ipsilateral $\mathrm{ON}$ to introduce instruments in-between the optic apparatus.

\section{Limitations}


There are several limitations inherent to the retrospective design of the study and lack of randomization in the operative decision to perform an ipsilateral or contralateral approach. Some borderline significant results may be due to insufficient number of patients included in this series.

\section{Conclusions}

Tuberculum sellae meningiomas usually show asymmetric growth with a dominant side. Most of TSMs result in ipsilateral optic canal involvement which leads to severe visual disturbances. A safe resection of the meningioma by approaching the tumor from the opposite side of the invaded canal is feasible with minimal manipulation of the compromised optic nerve. Tumor resection through a contralateral approach seems to provide better visual outcome and tumor control at the cost of increased olfactory nerve disorders.

\section{Declarations}

Conflict of interest: None of the authors disclose any conflict of interest in relation with this study.

Disclosure of Funding: None of the authors disclose any financial disclosure in relation with this study.

Availability of data and material: My manuscript has data included as electronic supplementary material.

Code availability: Not applicable

ORCID ID: 0000-0003-2995-4820

Ethics approval: the French Neurosurgical College Institutional Review Board approved this study (reference: IRB00011687 - College de neurochirurgie IRB \#1: 2020/33).

Consent to participate: Informed consent was obtained from all patients

Consent for publication: All patients agreed for publication

Submission Statement: This manuscript has not been previously published in whole or in part or submitted elsewhere for review.

Author contributions: All authors have made substantial contributions so as to qualify for authorship, and have read and approved the final version of this manuscript.

- LT, TG, HD: conception and design of the study

- GB, KF, SB: acquisition of data

- LT, MB: analysis and interpretation of data

- LT, GB: drafting the Article

- SF, TG, HD: critically revising the Article 


\section{References}

1. Al-Mefty O, Smith RR. Tuberculum sellae meningiomas. Meningiomas. Raven Press, New York. 1991.

2. Arai H, Sato K, Okuda O, Miyajima M, Hishii M, Nakanishi H, et al. Transcranial transsphenoidal approach for tuberculum sellae meningiomas. Acta Neurochir (Wien) 2000;142(7):751-6 [discussion 6-7].

3. Bander ED, Singh H, Ogilvie CB, et al. Endoscopic endonasal versus transcranial approach to tuberculum sellae and planum sphenoidale meningiomas in similar cohort of patients. $J$ Neurosurg. 2018;128: 40-48.

4. Benjamin V, Russell SM. The microsurgical nuances of resecting tuberculum sellae meningiomas. Neurosurgery. 2005;56(2 Suppl):411-417.

5. Bergland R. The arterial supply of the human optic chiasm. J Neurosurg. 1969;31:327-334.

6. Cardali S, Romano A, Angileri FF, Conti A, La Torre D, de Divitiis O, et al. Microsurgical anatomic features of the olfactory nerve: relevance to olfaction preservation in the pterional approach. Neurosurgery 2005;57(1 Suppl.):17-21

7. Comert A, Ugur HC, Kahilogullar G, Comert E, Elhan A, Tekdemir I. Microsurgical anatomy for intraoperative preservation of the olfactory bulb and tract. J Craniofac Surg 2011;22(3):1080-2.

8. Chi JH, McDermott MW. Tuberculum sellae meningiomas. Neurosurg Focus. 2003;14(6):e6.

9. Couldwell WT, Weiss MH, Rabb C, et al. Variations on the standard transsphenoidal approach to the sellar region, with emphasis on the extended approaches and parasellar approaches: surgical experience in 105 cases. Neurosurgery. 2004;55(3):539-547.

10. Dusick JR, Esposito F, Kelly DF, et al. The extended direct endonasal transsphenoidal approach for nonadenomatous suprasellar tumors. J Neurosurg. 2005;102(5):832-841.

11. EngelhardtJ, Namaki $\mathrm{H}$, Mollier $\mathrm{O}$, et al.

Contralateral transcranial approach to tuberculum sellae meningiomas: Long-Term Visual Outcomes and Recurrence Rates. World Neurosurg. 2018;116:e1066-e1074. doi: 10.1016/j.wneu.2018.05.166.

12. Fahlbusch R, Schott W. Pterional surgery of meningiomas of the tuberculum sellae and planum sphenoidale: surgical results with special consideration of ophthalmological and endocrinological outcomes. J Neurosurg. 2002;96(2):235-243.

13. Galal A, Faisal A, Al-Werdany $\mathrm{M}$, et al. Determinants of postoperative visual recovery in suprasellar meningiomas. Acta Neurochir (Wien). 2010;152(1):69-77.

14. Ganna A, Dehdashti AR, Karabatsou K, Gentili F. Fronto-basal interhemispheric approach for tuberculum sellae meningiomas; long-term visual outcome. Br J Neurosurg 2009;23(4):422-30.

15. Grisoli F, Diaz-Vasquez P, Riss M, et al. Microsurgical management of tuberculum sellae meningiomas. Results in 28 consecutive cases. Surg Neuro/ 26(1):37-44.

16. Hannequin P, Paviot A, Chaussy $\mathrm{O}$, et al. Olfaction preservation after removal of large tuberculum sellae meningiomas via a superior interhemispheric approach. A quantitative and qualitative study. Neurochirurgie. 2015;61(5):318-23. 
17. Jallo Gl, Benjamin V. Tuberculum sellae meningiomas: microsurgical anatomy and surgical technique. Neurosurgery. 2002;51(6):1432-1439.

18. Jang WY, Jung $S$, Jung $T Y$, et al. The contralateral subfrontal approach can simplify surgery and provide favorable visual outcome in tuberculum sellae meningiomas. Neurosurg Rev. 2012;35:601608.

19. Kim TW, Jung S, Jung TY, Kim IY, Kang SS, Kim SH. Prognostic factors of postoperative visual outcomes in tuberculum sellae meningioma. Br J Neurosurg. 2008;22(2):231-4.

20. Kitano M, Taneda M, Nakao Y. Postoperative improvement in visual function in patients with tuberculum sellae meningiomas: results of the extended transsphenoidal and transcranial approaches. J Neurosurg. 2007;107(2):337-346.

21. Kondo $S$, Okada $Y$, Iseki $H$, et al. Thermological study of drilling bone tissue with a high-speed drill. Neurosurgery 46(5):1162-8.

22. Koutourousiou M, Fernandez-Miranda JC, Stefko ST, et al. Endoscopic endonasal surgery for suprasellar meningiomas: experience with 75 patients. J Neurosurg. 2014;120:1326-1339.

23. Lee $\mathrm{S}$, Hong $\mathrm{SH}$, Cho YH et al. Anatomicalorigin of tuberculum sellae meningioma: off-midline location and its clinical implications. World Neurosurg. 2016;89:552-61. doi: 10.1016/j.wneu.2016.02.016.

24. Li X, Liu M, Liu Y, Zhu S. Surgical management of tuberculum sellae meningiomas. J Clin Neurosci. 2007;14(12):1150-1154.

25. Liu JK, Christiano LD, Patel SK, et al. Surgical nuances for removal of tuberculum sellae meningiomas with optic canal involvement using the endoscopic endonasal extended transsphenoidal transplanum transtuberculum approach. Neurosurg Focus. 2011;30:E2.

26. Liu Y, Chotai S, Ming C, et al. Characteristics of midline suprasellar meningiomas based on their origin and growth pattern. Clin Neurol Neurosurg.2014;125:173-81. doi: 10.1016/j.clineuro.2014.08.002.

27. Mathiesen T, Kihlstrom L. Visual outcome of tuberculum sellae meningiomas after extradural optic nerve decompression. Neurosurgery. 2006;59(3):570-576.

28. Nakamura M, Roser F, Struck M, Vorkapic P, Samii M. Tuberculum sellae meningiomas: clinical outcome considering different surgical approaches. Neurosurgery. 2006;59(5):1019-1028.

29. Nanda A, Ambekar S, Javalkar V, Sharma M. Technical nuances in the management of tuberculum sellae and diaphragma sellae meningiomas. Neurosurg Focus. 2013;35:E7.

30. Nozaki K, Kikuta K, Takagi Y,Mineharu Y, et al. Effect of early optic canal unroofing on the outcome of visual functions in surgery for meningiomas of the tuberculum sellae and planum sphenoidale. Neurosurgery. 2008;62(4):839-844.

31. Otani N, Muroi $\mathrm{C}$, Yano $\mathrm{H}$, et al. Surgical management of tuberculum sellae meningioma: role of selective extradural anterior clinoidectomy. Br J Neurosurg 2006;20(3):129-138. 
32. Pamir MN, Ozduman $\mathrm{K}$, Belirgen $\mathrm{M}$, et al. Outcome determinants of pterional surgery for tuberculum sellae meningiomas. Acta Neurochir (Wien) 2005;147(11):1121-1130.

33. Rhoton A Jr. The sellar region. Neurosurgery. 2002;51(4 suppl):S335-S374.

34. Romani R, Laakso A, Kangasniemi M, et al. Lateral supraorbital approach applied to tuberculum sellae meningiomas: experience with 52 consecutive patients. Neurosurgery. 2012;70:1504-1519.

35. Sade B, Lee JH. High incidence of optic canal involvement in tuberculum sellae meningiomas: rationale for aggressive skullbase approach. Surg Neurol. 2009;72(2):118-123.

36. Schick U, Hassler W. Surgical management of tuberculum sellae meningiomas: involvement of the optic canal and visual outcome. J Neurol Neurosurg Psychiatry. 2005;76(7):977-983.

37. Simpson D. The recurrence of intracranial meningiomas after surgical treatment. JNeurol Neurosurg Psychiatry 20(1):22-39.

38. Terasaka S, Asaoka K, Kobayashi H, Yamaguchi S. Anterior interhemispheric approach for tuberculum sellae meningioma. Neurosurgery 2011;68:84-8; discussion 88-9.

39. Yasargil MG. Microneurosurgery. Vol. 1. Chapter 1: Operative anatomy. Thieme Medical Publishers. 1984.

\section{Tables}

\section{Table 1: Population study characteristics.}




\begin{tabular}{|c|c|}
\hline Characteristic & $\mathrm{Nb}$ \\
\hline Male / Female (\%) & $11(12) / 83(88)$ \\
\hline Mean age in years (range) & $55(21-86)$ \\
\hline \multicolumn{2}{|l|}{ Clinical features (\%) } \\
\hline visual acuity loss & $80(85)$ \\
\hline - $\quad$ unilateral & $57(61)$ \\
\hline - $\quad$ bilateral & $23(24)$ \\
\hline visual field defects & $88(94)$ \\
\hline - $\quad$ unilateral & $42(45)$ \\
\hline - $\quad$ bilateral & $46(49)$ \\
\hline headaches & $14(15)$ \\
\hline anosmia & $3(3)$ \\
\hline seizure & $1(1)$ \\
\hline incidental & $6(6)$ \\
\hline Symptom duration in months (range) / median & $8(0.5-48) / 6$ \\
\hline \multicolumn{2}{|l|}{ Radiological features (range) / median } \\
\hline Mean diameter in mm & $25(10-78) / 24$ \\
\hline Mean volume in cc & $5.6(0.7-14.5) / 4.1$ \\
\hline \multicolumn{2}{|l|}{ Surgical Features (\%) } \\
\hline Ipsilateral approach & $43(46)$ \\
\hline Contralateral approach & $36(38)$ \\
\hline Non applicable* & $15(16)$ \\
\hline \multicolumn{2}{|l|}{ Extent of Resection (\%) } \\
\hline Simpson Grade II & $70(74)$ \\
\hline Simpson Grade IV & $24(26)$ \\
\hline \multicolumn{2}{|l|}{ World Health Organization Grade } \\
\hline Grade I & $86(91)$ \\
\hline Grade II & $8(9)$ \\
\hline Mean Follow-Up (IC 95\%) / median & $59(2-210) / 44$ \\
\hline
\end{tabular}


* Patients whom presented midline lesions compromising bilateral vision. They underwent a right-sided craniotomy. The "non-applicable" patients were separated out from the data set for the logistic regression analysis

Table 2: Pre- and intraoperative predictive factors of non-recuperation of a preoperative visual acuity loss in tuberculum sellae surgery: univariate and multivariate analysis.

\begin{tabular}{|c|c|c|c|c|}
\hline \multirow[t]{2}{*}{ Predictive Factors } & \multicolumn{2}{|c|}{ Univariate Analysis } & \multicolumn{2}{|c|}{ Multivariate Analysis } \\
\hline & $\begin{array}{l}\mathrm{p}- \\
\text { value }\end{array}$ & OR [IC95\%] & $\begin{array}{l}\mathrm{p}- \\
\text { value }\end{array}$ & OR [IC95\%] \\
\hline Age (years) & 0.009 & $\begin{array}{l}1.049[1.012- \\
1.087]\end{array}$ & 0.033 & $\begin{array}{l}1.067[1.005- \\
1.132]\end{array}$ \\
\hline Visual symptoms duration (years) & 0.040 & $\begin{array}{l}1.046[1.002- \\
1.092]\end{array}$ & 0.006 & $\begin{array}{l}9.422[1.902- \\
46.679]\end{array}$ \\
\hline Preoperative visual acuity loss & 0.022 & $\begin{array}{l}4.835[1.260- \\
18.549]\end{array}$ & 0.002 & $\begin{array}{l}27.617[3.349- \\
227.729]\end{array}$ \\
\hline Tumor volume & 0.199 & $\begin{array}{l}0.935[0.844- \\
1.036]\end{array}$ & 0.003 & $\begin{array}{l}0.726[0.587- \\
0.897]\end{array}$ \\
\hline Optic canal involvement & 0.065 & $\begin{array}{l}0.491[0.231- \\
1.044]\end{array}$ & 0.093 & $\begin{array}{l}0.398[0.135- \\
1.168]\end{array}$ \\
\hline $\begin{array}{l}\text { Surgical approach (Contralateral vs } \\
\text { Ipsilateral) }\end{array}$ & 0.870 & $\begin{array}{l}1.091[0.385- \\
3.092]\end{array}$ & & \\
\hline $\begin{array}{l}\text { Extent of resection } \\
\text { (Simpson Grade } 2 \text { vs } 4 \text { ) }\end{array}$ & 0.005 & $\begin{array}{l}4.061[1.529- \\
10.786]\end{array}$ & 0.012 & $\begin{array}{l}18.945[1.918- \\
187.179]\end{array}$ \\
\hline
\end{tabular}

Table 3: Pre- and intraoperative predictive factors of non-recuperation of a preoperative visual field defect in tuberculum sellae surgery: univariate and multivariate analysis. 


\begin{tabular}{|c|c|c|c|c|}
\hline \multirow[t]{2}{*}{ Predictive Factors } & \multicolumn{2}{|c|}{ Univariate Analysis } & \multicolumn{2}{|c|}{ Multivariate Analysis } \\
\hline & $\begin{array}{l}\mathrm{p}- \\
\text { value }\end{array}$ & OR [IC95\%] & $\begin{array}{l}\mathrm{p}- \\
\text { value }\end{array}$ & OR [IC95\%] \\
\hline Age & 0.001 & $\begin{array}{l}1.063[1.026- \\
1.102]\end{array}$ & 0.007 & $\begin{array}{l}1.059[1.016- \\
1.105]\end{array}$ \\
\hline Depth of the VFD & 0.000 & $\begin{array}{l}7.050[2.514- \\
19.774]\end{array}$ & 0.000 & $\begin{array}{l}7.909[2.585- \\
24.196]\end{array}$ \\
\hline Visual symptoms duration & 0.394 & $\begin{array}{l}1.017[0.978- \\
1.058]\end{array}$ & - & - \\
\hline Tumor volume & 0.674 & $\begin{array}{l}0.976[0.870- \\
1.094]\end{array}$ & - & - \\
\hline Optic canal involvement & 0.421 & $\begin{array}{l}1.348[0.652 \text { - } \\
1,534]\end{array}$ & - & - \\
\hline $\begin{array}{l}\text { Surgical approach (Contralateral vs } \\
\text { Ipsilateral) }\end{array}$ & 0.040 & $\begin{array}{l}0.526[0.285- \\
0.971]\end{array}$ & 0.088 & $\begin{array}{l}0.379[0.125- \\
1.154]\end{array}$ \\
\hline $\begin{array}{l}\text { Extent of resection } \\
\text { (Simpson Grade } 2 \text { vs } 4 \text { ) }\end{array}$ & 0.385 & $\begin{array}{l}0.648[0.244- \\
2.789]\end{array}$ & - & - \\
\hline
\end{tabular}

VFD: visual field defect

Figures 

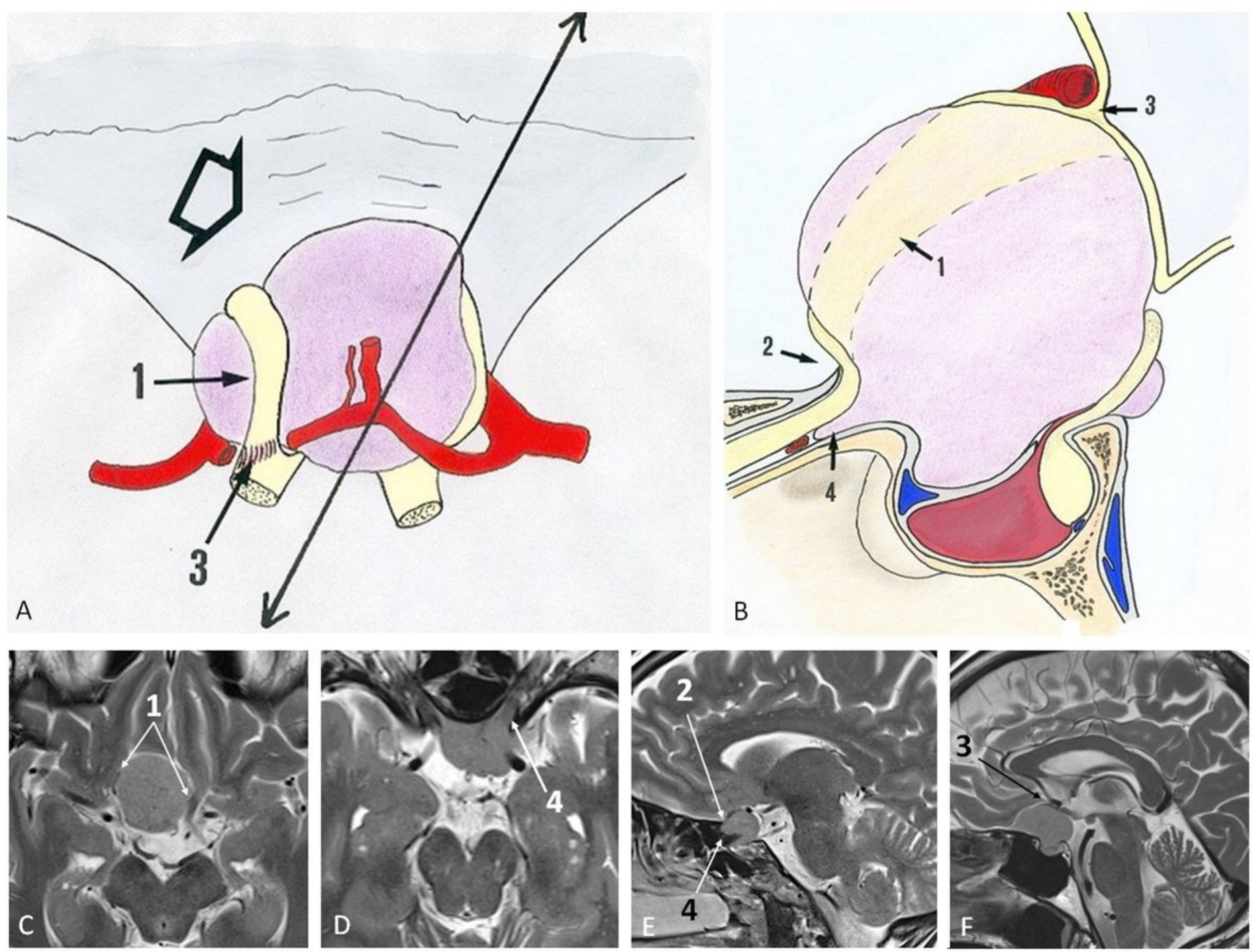

\section{Figure 1}

The anatomical critical compression points of the optic nerve caused by tumor growth in tuberculum sellae meningiomas. A \& B: Schematic superior and lateral views of a tuberculum sellae meningioma and its relations with the surrounding neurovascular structures. C, D, E \& F: Preoperative t2-weighted axial and sagittal MRI images illustrating the compression points of the optic nerve (ON) due to tuberculum sellae meningiomas. 1- Direct compression of the $\mathrm{ON}$ by the tumor 2-Compression of the ON against the falciform ligament superiorly secondary to the TSM extension to the inferomedial part of the optic canal 3-Compression of the ON between the tumor and the Anterior Cerebelar Artery 4-Compression of the ON due to optic canal involvement by the tumor 

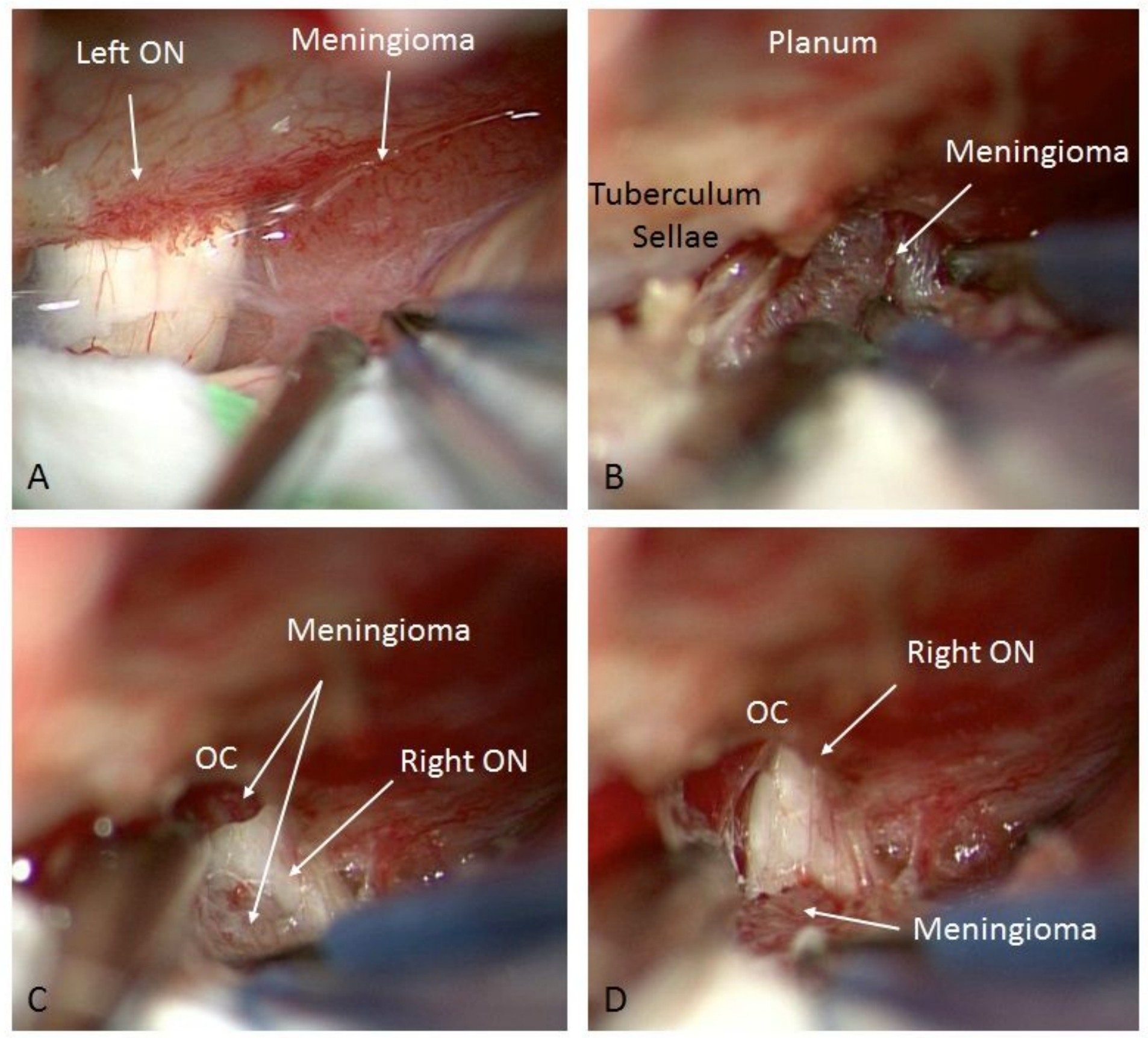

Figure 2

Operative view of a tuberculum sellae meningioma resection through an ipsilateral approach. A: While operating through an ipsilateral approach, the optic nerve (ON) is crossing the operative window in the foremost position; the meningioma is partly hidden by the ON. B\&C: The access of the inferior-medial side of the ipsilateral $\mathrm{ON}$ might be challenging in this configuration, which result in increased manipulation of the compromised ON. D: To minimize the risk of postoperative impaired visual outcome, a tumor residue has been left behind the compromised ON. 

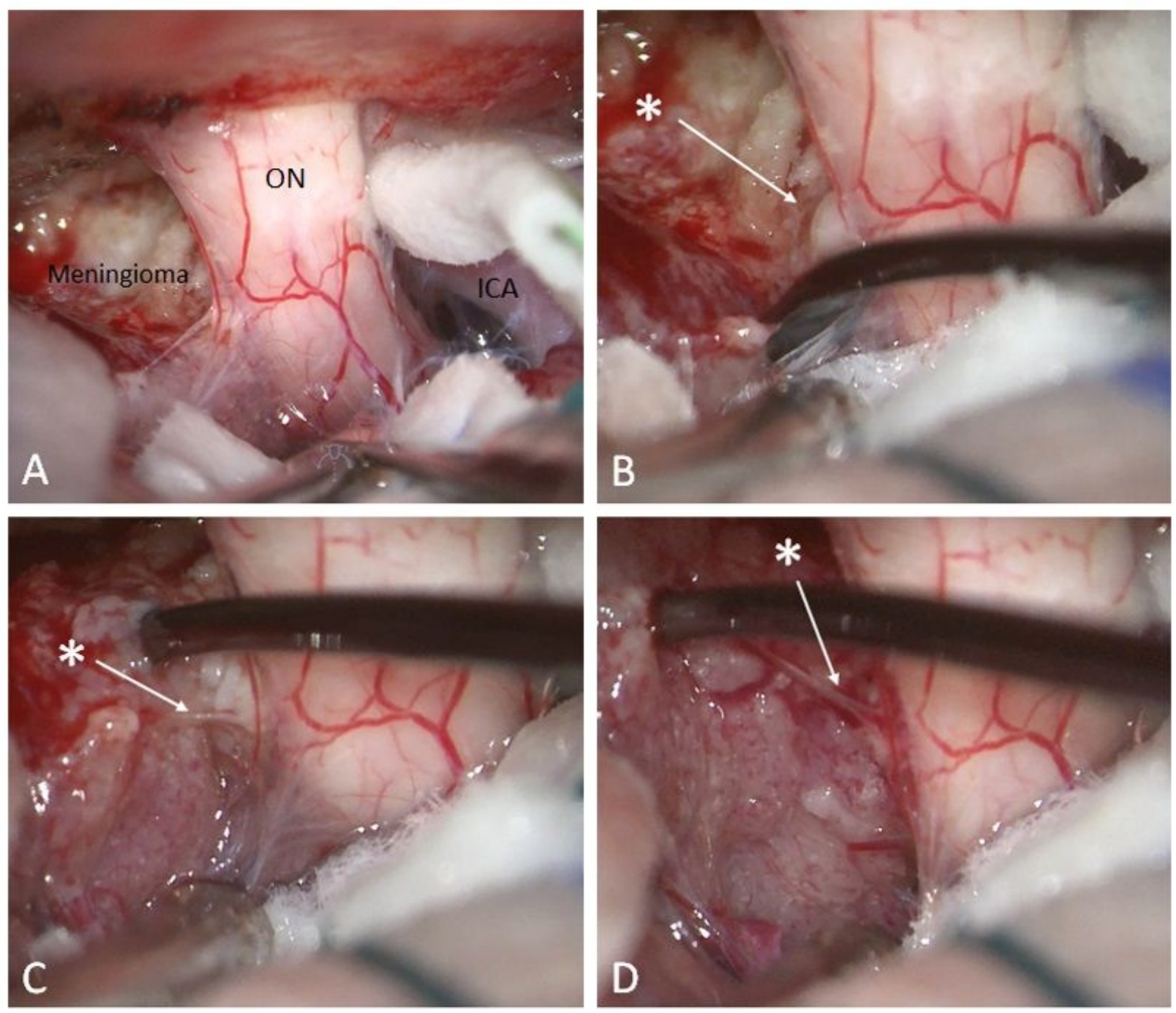

\section{Figure 3}

Extra-arachnoidal dissection of a tuberculum sellae meningioma. Operative view. A\&B: The central debulking of the meningioma facilitates the identification of the natural capsuloarachnoid dissection plan between the tumor and suprasellar arachnoid elements, within which run the feeding arteries of the optic apparatus (white asterisk). C\&D: A sharp dissection is performed along that plane and the optic sulcus to expose the inferomedial aspect of the $\mathrm{ON}$, while preserving its vascular supply (white asterisk). 

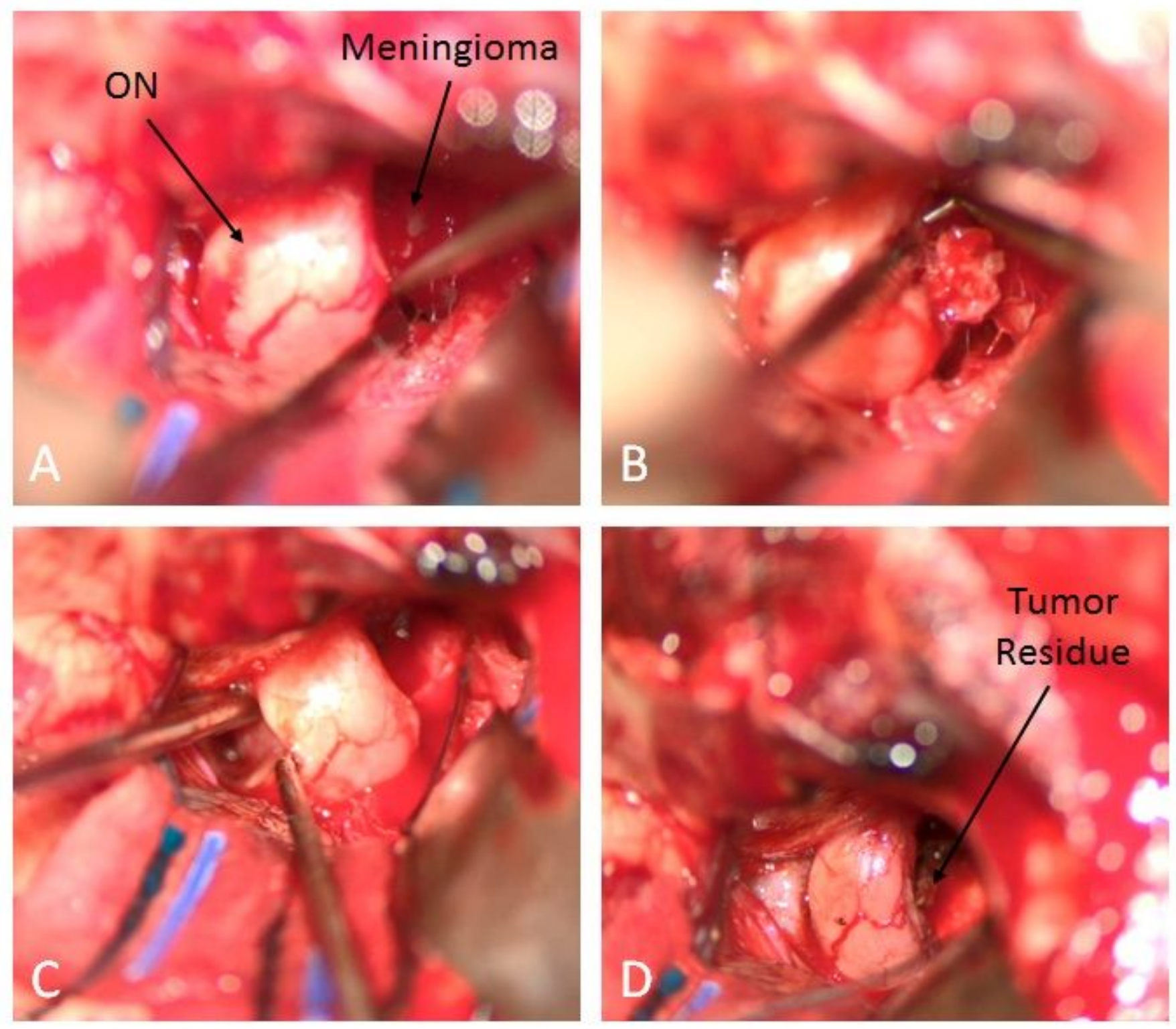

\section{Figure 4}

Resection of a tuberculum sellae meningioma invading the right optic canal through a contralateral approach. Operative view. A: The left optic nerve $(\mathrm{ON})$ and left border of the meningioma's capsule are accessed through a left-side frontolateral approach. B: The tumor debulking is accomplished without manipulation of the non-copromised ON (left one). C: The extra-arachnoidal dissection of the tumor exposes the inferomedial aspect of the compromised ON (right one) and invaded optic canal (OC). D: The intracanalar part of the tumor is removed by gentle traction. Finally, the posterior part of the tumor is resected. 


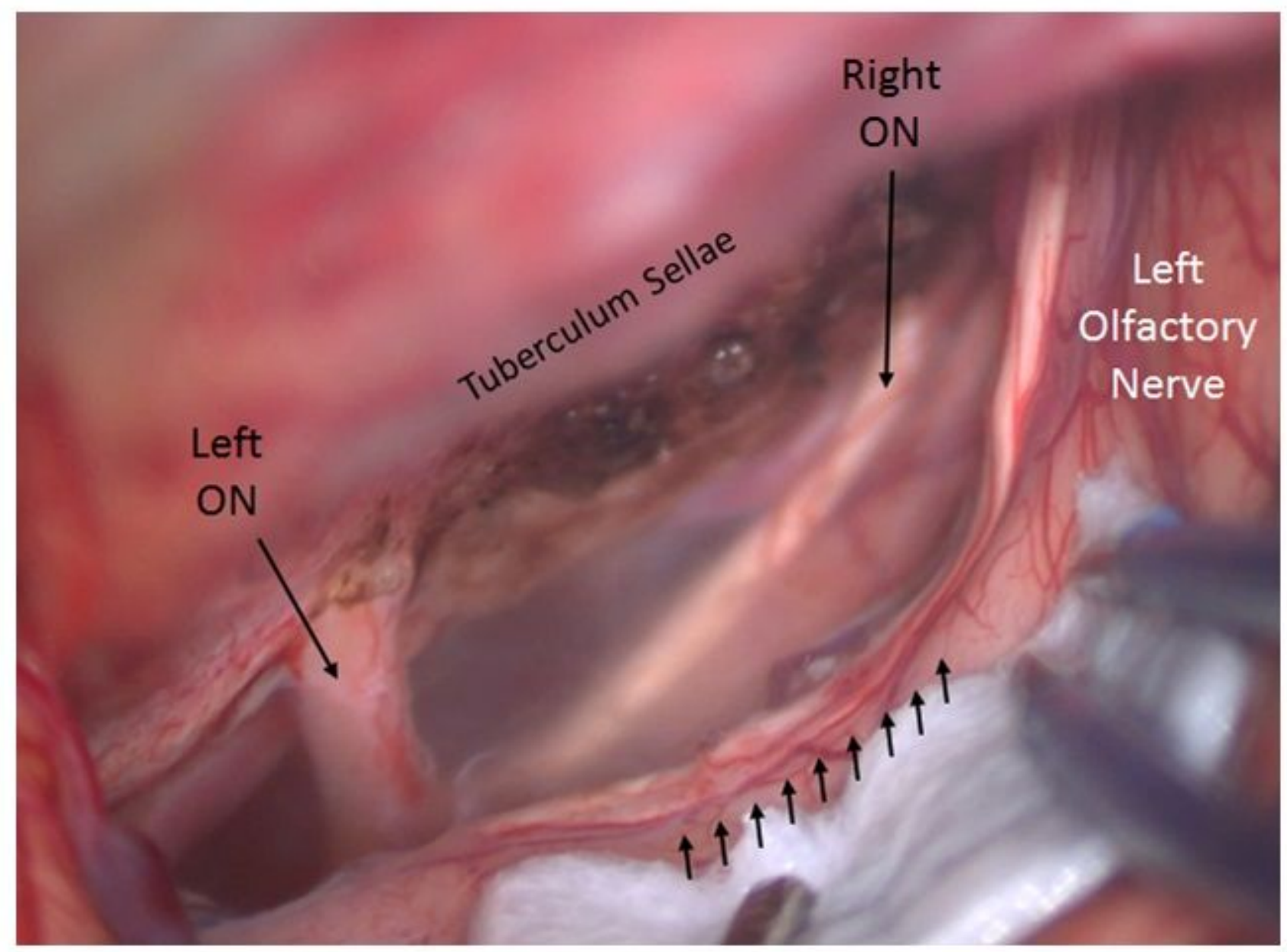

\section{Figure 5}

Left olfactory nerve damage after tuberculum sellae meningioma resection through an ipsilateral approach. A55 years-old patient underwent tuberculum sellae meningioma resection through an ipsilateral approachlt appeared that the left olfactory nerve suffered from direct compression by the meningioma, shown by the imprint on the nerve after tumor resection, as well as intraoperative tearing by manipulation of the tumor in close vicinity of the olfactory nerve. This patient retained long term olfactory disturbances. 


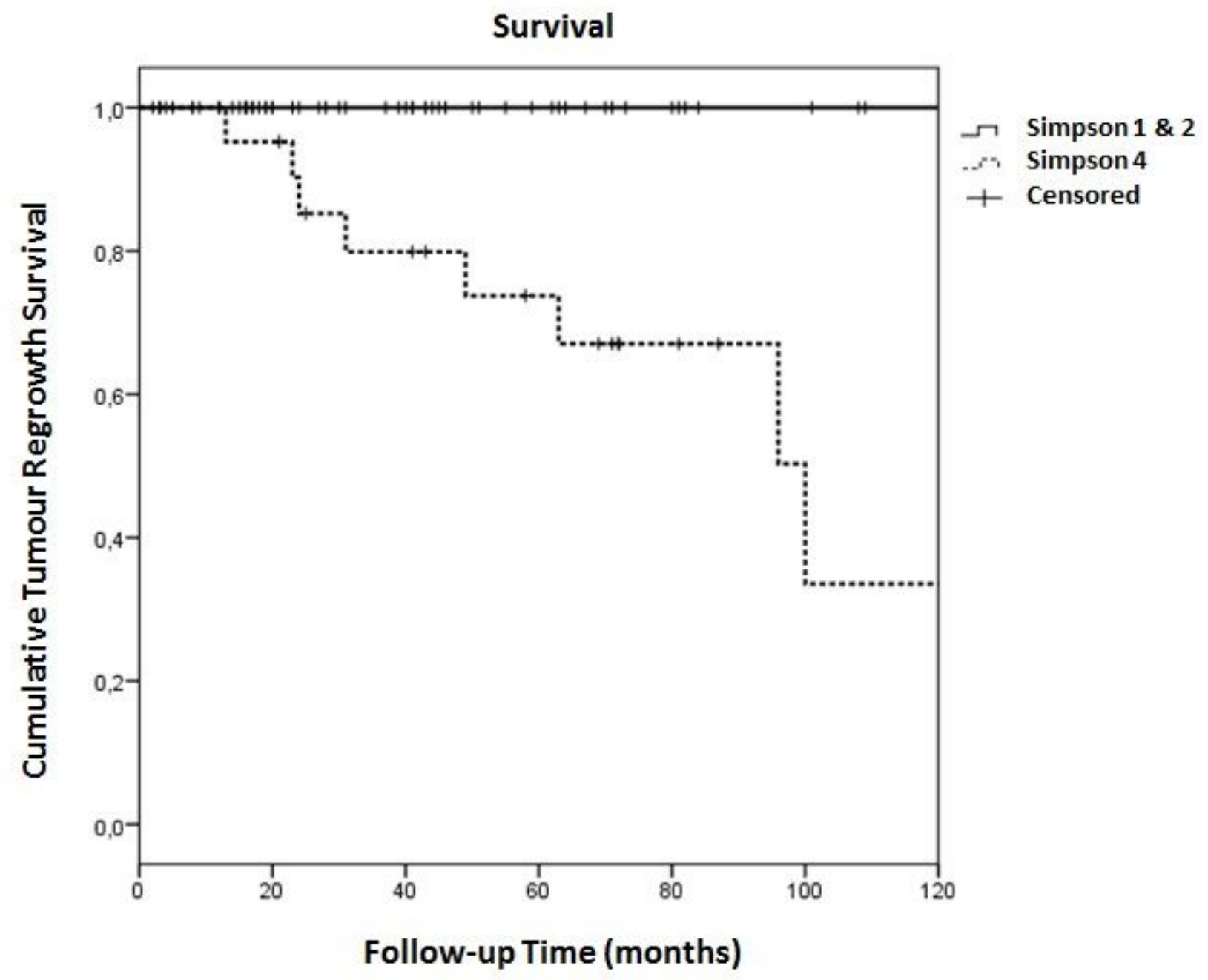

Figure 6

Kaplan-Meier analysis of tumor control during follow-up after Gross total (Simpson 1\&2 - continuous line) and subtotal resection (Simpson 4 - dotted line). The 2-, 5- \& 7-year tumor progression free survival (PFS) were 100\% $(n=41), 100 \%(n=22) \& 100 \%(n=11)$ in the GTR group, and $85 \%(n=17), 74 \%(n=11)$ \& $67 \%(n=5)$ in the Subtotal resection group, respectively $(p=.00)$. 